\title{
Impact of coastal protection systems on marine ecosystems
}

\author{
Iulia Alina Anton ${ }^{1, *}$, Mariana Panaitescu ${ }^{1}$, Fanel-Viorel Panaitescu ${ }^{1}$, and Simona Ghiță$^{1}$ \\ ${ }^{1}$ Constanta Maritime University, Faculty of Naval Electromechanics, 104 Mircea cel Bătrân, 900663 Constanta, Romania
}

\begin{abstract}
Various solutions, which consist of numerous techniques, technologies and planning measures, are testing for reduction shoreline erosion, precisely for protection shore against waves attack. These methods may affect the site's geology and geomorphology, involving changes of the habitats in the site. Coastal defense projects and ideas must take into account the structure and functions of protected natural areas and their conservation objectives in order to avoid threatening the species and/or habitats on the site. The ecological impacts expected from coast protection structures on short-term are mostly negative, may disturbance the birds from their habitat, and destruct the marine coastal habitats with their own flora and fauna. In this study, we are indicating the effects of coastal protection measures on the ecosystem. Therefore, we present a part of methods applied or which will be apply on the Romanian shoreline and the effects that have an impact on the species and/or habitats on the site. The methods referred to "hard" methods so to harder the shore with fixed structure (bulkhead, seawall, revetment, breakwaters, sills or groins) or "soft" methods like beach nourishment that is not a sustainable method in time. The protection structures like breakwaters and groins trap or add sand and will change the beach geometry this means that can introduce new artificial material, which is extensively and rapidly colonized by algae and marine animals. In the cases of beach nourishment, under water sand nourishment and mudflat recharge, there are impacts both at the borrow site (the sediment source) and the target site. In the zone of extraction of borrow, sediments appear a damage and mortality to the benthos. Finally, it can conclude that some of the effects are beneficial for socio-economic aspect, but it is important also, the environment, which can bring bad consequences for earth landscape and make the ecosystem, be unbalanced.
\end{abstract}

\section{Introduction}

The Romanian coastal zone is in the East of Romanian territory, with a length of $244 \mathrm{~km}$. This area is divided by the type of sediment cells in two sections: North and South. To protect and maintain these sediment cells have taken important decisions on the coastal zone, such as the construction of hydraulic structures (coastal defense structures) in order to dissipate wave energy. All these changes can lead to the destruction of habitats, continuous coastal erosion, water pollution and the depletion of natural resources.

The sustainable development of the coastal zone requires the management of economic development in harmony with the protection and restoration of the environment, with social benefits, which implies the arrangement and protection of these areas. The protection of Romania's coastal zone is one of the priorities of the governance programs, as the studies and projects carried out over the years have shown that this area is increasingly subject to the impact of environmental factors and human activities. The right solution is selected according to coastal characteristics, human use or needs and availability of materials. It is also important to reduce any adverse effects caused by the implementation of coastal work.

This is also the case with the Eforie area, where a significant erosion rate a few years ago, which required intervention measures. In the following, we present the adverse effects that affect the coastal area following coastal coastal protection decisions.

The coastal zone of Eforie area is localized in the South Unit of Romanian coastal zone and is caracterized by biodiversity of Black Sea which is considered a "unicum hydrobiologicum" because of its physico-chemical and biological peculiarities, especially the presence of the $\mathrm{H}_{2} \mathrm{~S}$ at $180 \mathrm{~m}$ depth.

Black Sea biocenosis is composed of about 5.000 species (bacteria, protozoa, plants, fungi, animals), which 3.244 species have been recorded in the Romanian coastal areas.

The Eforie coastal zone has particular importance in terms of the variety of natural habitats (sand dunes, salty, wetlands, coastal cliffs, etc.) and high biodiversity. Among existing coastal marine habitats

\footnotetext{
${ }^{*}$ Corresponding author: iulia.anton@,cmu-edu.eu
} 
present in the study area we mention the following: submerged areas with shallow water (infralitoral), sandy or rocky shorelines (mediolitoral), sand dunes, salty meadows, salt marshes, coastal cliffs, etc.).

The biotic components directly affected by the application of erosion protection structures are macrophitobenthos and zoobenthos. The largest number of algal macrophytes are focuses on 1-5 m depths and are occupying the hard substrate at the bottom of the marine basin.

Algal macrophlora has an important ecological role, representing a biological nutrient treatment factor, shelter for epiphytic algae and associated fauna and trophic basis for invertebrates and marine fish. Environmental changes have as a result the changing hydrochemical parameters, clogging substrate rough, increasing quantities of biogenic substances, the sharp decrease in water transparency and the spillage of petroleum residues. All this changes lead to the development of species of macrophytes tolerant opportunistic (Enteromorpha, Cladophora, Ceramium). In the Black Sea there is a sharp decrease in the number of marine perennial plant species (Cystoseira, Phyllophora, Zostera).

Zoobenthos is composed of animal populations that live up to a depth of 180-200 m. Zoobenthos, a status indicator of eutrophication and shows a positive trend of biodiversity growth in the Romanian Black Sea coast. The qualitative assessment led to the identification of 75 macrozoobenthic species.

\section{Types of coastal protection structures and their impact on the shore}

In the South Sector of Romanian coastal zone has been used the most coastal protection structures, like dikes, groyne fields and seawalls. This is the case of Eforie area which is caracterized by hard and soft protection works.

The "hard protection works", can be divided into three categories:

- $\quad$ Shore consolidation works;

- $\quad$ Transversal protection works (groins, dykes)

- Longitudinal work in the sea : breakwaters and other types, figure 1;

The "soft protection works" are represented by artificial nourishment and dune consolidation. This type of protection is used alongside "hard defenses" but involves rises in coastal protection schemes and the biodiversity of the area undergoes major changes. [1]

Coastal structures (hard works) which are based on shore consolidation works have the main purpose of dissipation direct wave action. It is important that they do not lead to erosion in their foundation area or in the front beach. These types of works hinders the natural aspect of the beaches and the tourist use.[1]

Transversal works, more precisely the groins (figure 2), are the main purpose of stopping the transport of sediments along the beach, which implies the development of upstream accumulations and erosion on their downstream side. Their effectiveness stream with suspended alluviums and the physical possibility of intersecting them. [2]

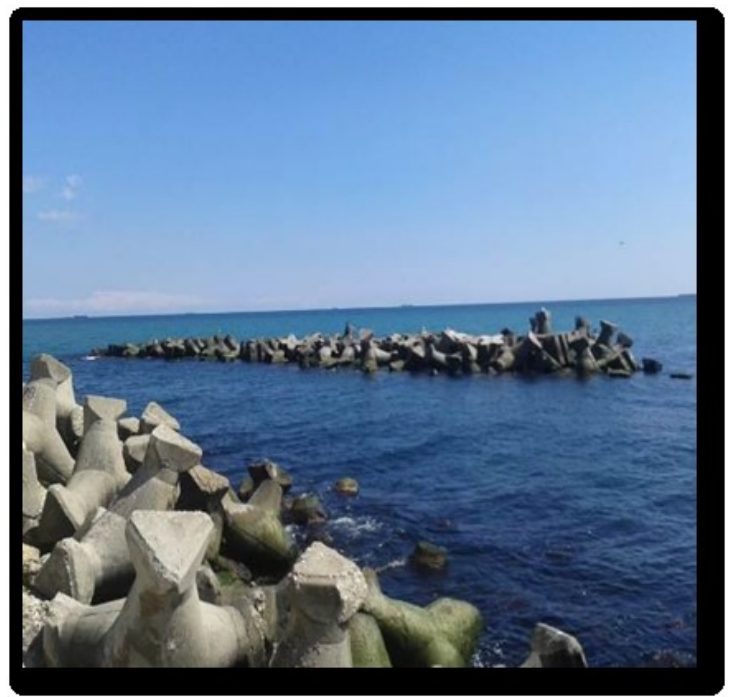

Fig. 1. Detached Breakwaters [1].

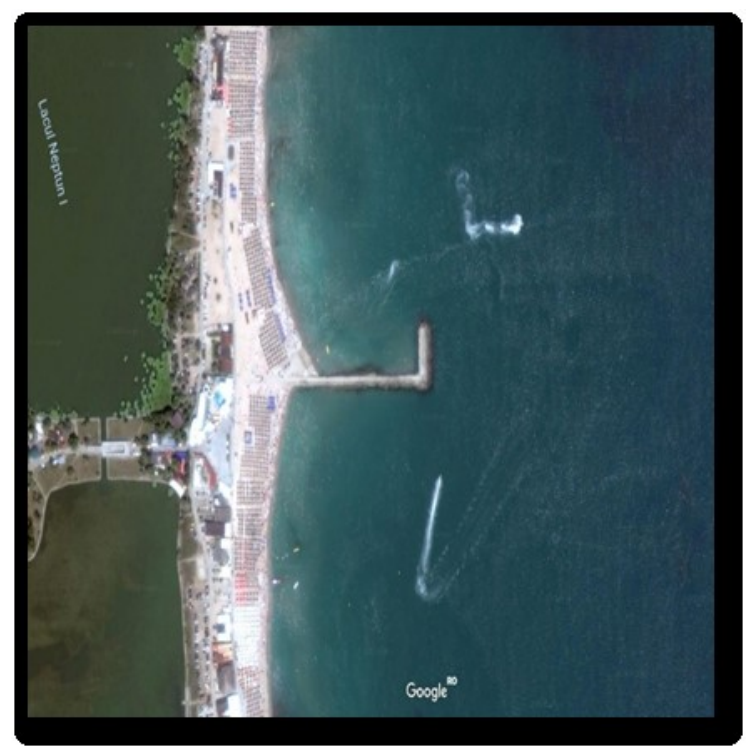

Fig. 2. Groines on Romanian Black Sea Coast.

Longitudinal works interferes with the wave propagation by intercepting the incident energy flow. Part of this energy is distributed widely, a portion is dissipated in the mass of the building, and the rest of the energy is transmitted through/over the dikes.[1]

To prove the above, in the following is a case from the Romanian coastal area (Mamaia Bay) in which the shore is protected with "hard protection systems", breakwater systems. For this, we use the 2D package of MIKE. MIKE 21 used for modelling coasts and seas and cover all physical and environmental aspects of marine modelling.

MIKE 21 PMS (Parabolic Mild-Slope Model) is a linear refraction-diffraction model based on a parabolic approximation to the elliptic mild slope equation. For this case, we take in account the different effects of refraction and shoaling because the 
depth varying and diffraction along the perpendicular to the predominant wave direction.[1].

The principal equation on which is based the model is the elliptic mild-slope equation:

$$
\Delta \cdot\left(C C_{g} \Delta \phi\right)+\left(k^{2} C C_{g}+i \omega W\right) \phi=0
$$

where $\Delta$ is two-dimensional gradient operator, $C(x, y)$ is phase speed, $C_{g}(x, y)$ is group velocity, $\phi(x, y)$ is mean free surface velocity potential.

The results can be seen in the next figures, figure 3 and 4 . The wave heights are changed at the time of a collision with a detached breakwater and how the phenomenon of diffraction appears because of this phenomenon.[1]

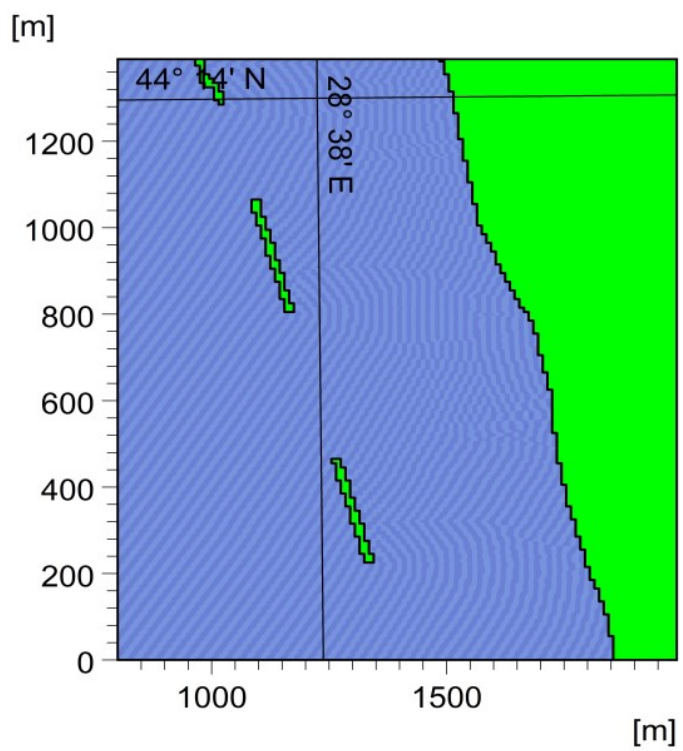

Scale 1:127400

Fig. 3. Refraction and difraction on Mamaia Bay.

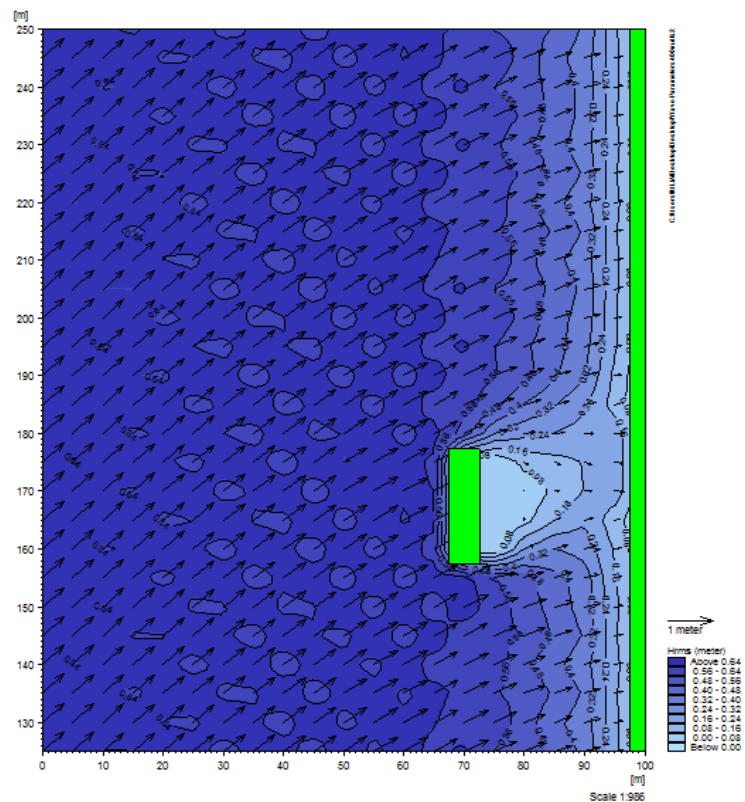

Fig. 4. The impact of breakwater systems on shore [1].

\section{Environmental impacts of coastal defense structures}

The environmental impacts of coastal protection works can be discussed on short-term (during construction and maintenance phase) and long-term impacts (during operational phase). The hard and soft protection works has different impacts on the biodiversity of the area, so will be separated discussed in the following.

These environmental aspects on the marine environment are based on the findings of the Appropriate Assessment Study of the project "The Protection and Rehabilitation of the Southern Black Sea Coast in the Constanta Municipality Area (Mamaia South, Tomis North, Tomis Centre and Tomis South) and Eforie North Area". [5]

Impact can affect fauna, flora and benthic habitats on large areas, as well as pelagic species in the immediate vicinity, destroying habitats that play an important role in the nourishment, reproduction and development of juveniles.

\subsection{Hard works}

On short-terms, in the phase on construction and maintenance the changes that appear depending on the area in which these structures are built. In this phase, the benthos substrate is affected negative or maybe loss. The local and adjacent zone is disturbed, especially the birds. For example, temporally, the noise and vibrations associated with the construction and also the visual impact affect negative different types of birds.

The new artificial substrate can be introduced which are colonized extensively by algae and marine animals and they lead to changes of important local biodiversity. In the maintenance phase, these new species can be temporarily disturbed, which implies a negative effect.

In conclusion, these type of works have a negative effect and temporally on this area. The new substrate introduces can influence negative or positive the zone but are permanent.

The long-term ecological impacts of hard coastal works are difficult to predict in a specific area quantitatively due to the variability of ecological systems makes it but there are some qualitative general impacts, as described below.

In terms of local scale impact, "hard work" systems, which are quite costly, modify the biodiversity of the area by creating new habitats of artificial hard substrates that can be characterized by rocky natural reefs densely populated by algae and epibenthic fauna.

Many pontic epibenthic species are the prey for fish and birds. The epibenthos can play a significant role in the bioaccumulation and transfer of contaminants through the food chain.

In the coastal waters of Eforie, 17 species of green algae, 15 red algae species and 5 species of brown 
algae have been inventoried over the last 10 years, and in the case of deep-seated zoobenthos there are polychaeta, amphipods, mollusks, crabs and fish.

For benthic species it is necessary to monitor the effects on key species such as Cystoseira, Corallina, Zostera, Donacilla, Donax, Pholas, throughout all construction period. In case of a severe negative impact, it is necessary to relocate the species to similar habitats.

As a result of these changes, the diversity of the area increases, but it is much smaller than the natural systems of rocky shores, and biodiversity is dominated by species with a wide range of dispersion. Moreover, the stages of individuals do not reach maturity as they resist these structures for a maximum of 2 years. Another negative impact is that resulting from the accumulation of sediment and net transport obtained by coastal protection structures that produce a significant reduction in benthic invertebrates. [4]

These types of hard work can also have a positive influence in the sense that they can be places for rest and feeding for birds.

Impact mitigation measures depend on the use degree of birds interest areas. If these areas are used for nesting, then avoiding the work during nesting is very important. Coastal marine waters are feeding grounds for aquatic bird species such as: Podiceps nigricollis, Podiceps cristatus, Gavia arctica, Gavia stelata, Larus spp., Sterna spp., Phalacrocorax pigmeus si Phalacrocorax carbo. From impact on the avifauna point of view at least the maintenance of the structure and the dynamics of these populations is appreciated, creating better habitat conditions.

Regarding regional scale impacts, segmented "hard work" structures (generally formed by a field of groynes or breakwaters) can alter the natural distribution of species by creating barriers to nonindigenous invasive species, especially pests. Consequently "hard work" structures have a significant negative impact. The presence of invasive species is relatively reduced due to the specific conditions in the Black Sea, which allow only a small number of species, endowed with specific qualities and special resistance to penetrate and live in the Black Sea. Immigrants must be able to use local ecological resources and form viable populations. The impact of invasive species on indigenous species in the Black Sea is often poorly known. In time, evidence of the invasion are the effects of these species with extremely strong impact on the autochthonous associations such as, gastropod Rapana venosa, bivalve Mya arenaria, ctenophore Mnemiopsis leidyi. These species actively influenced the biocoenosis asses sedimentary and hard substrate, thus contributing to reduction stocks of several fish or bivalve local species.[4]

\subsection{Soft coastal defence structures}

The "soft work" coastal defense structures cannot provide safe coastal protection to the coastal area unless they are used in conjunction with other protection systems. Their main role is to stabilize sediments from erosion processes through sediment storage and transport. The following impacts presented below will refer to the process of nourishment beaches.

Concerning the impact of these systems on shortterm, it is discussed in the two main phases, the construction phase and the maintenance phase.

In the first construction phase, there may be different visual and hearing disturbances for birds and nests, except in the case of seabirds that may be attracted to sediments if they contain good food. Hearing disturbances and vibrations because of the excavation process and innervation activities will remove organisms that are frequenting the area in search of food.

Bulldozers used to nourishment process of the areas can damage the vegetation of the dunes in the area and lead to compaction of the initial sediments. This involves a negative impact on the vascularization of plants and terrestrial fauna (arthropods) living in the affected area. In addition, if the sand is borrowed from the marine environment, there may be major negative effects on habitats and benthic species both in the place where they are located and in the location where it is extracted. As for the area of origin of the sand borrowed, the zone change occurs because of the extraction process and can cause damage to the benthic area that can even lead to mortality. Mortality is due to the inability of benthic species to move through the sediments that were at a certain point before extraction, as the resuspension of the fine sedimentary material (depending on the sea currents) and the choking of the biocenosis in the area, (Zostera noltii species).

Marine algae, macrophytes and angiosperms that resist clogging / burial by sediment will soon die due to turbidity in the area, which will completely block the penetration of light needed for photosynthesis.[4]

The effects described earlier may be more drastic when sand extraction takes place in a more remote area where there is a more populated area of benthic species, as the environment is more stable than the area near the shoreline and the hydrodynamics of the area is no longer so pronounced. In these areas, sediments can contain food, and when the sand is extracted, the rate of recovery of local communities decreases.

However, the resuspension of these sands will increase the concentration of nutrients in sediments (nitrates, phosphates), which implies microalgal blooms. These will change the water quality for both tourism and biocenosis in the area (leading to mortality from the hypoxia phenomenon).

The borrowed sand may also contain fine abiotic (mineral) sediments but may be rich in particulate and dissolved organic substances and accumulated toxic compounds that can be transported to the site.

Resuspension of sediment containing toxic substances leads to the appearance of these substances in the superficial water surface. Toxic substances will 
be taken over by aquatic filtration organisms that will be transported in higher trophic levels. Finally, contamination of species of economic and conservative interest (crustaceans, fish molluscs and marine mammals) is reached.

The impact on bird species in the construction phase will be a negative, but temporary, unlike the impact on flora and fauna that implies a negative and permanent effect. By re-establishing the area, there is a decrease in food availability as a result of the mortality of benthic organisms, the increase of turbidity and the recovery of affected habitats. All of this can reduce the number of birds in the area and recolonize the beach after the construction phase when in the area will be sediment with favorable food.

In the maintenance phase, "soft work" systems can lead to the maintenance of periodic innings. The effects will be similar to the effects seen at the construction stage that are generally negative.

In the longer term, the biodiversity of the area in which these works are located changes. Biodiversity involves the creation of new habitats that can offer at

some point suitable locations for various plants and animals associated with them. However, there is a drop in the initial habitat that can be of an ecological value superior to the newly created habitat.

Regarding the regeneration measures and the stabilization of the dunes, they do not produce a harmful impact on the natural environment by planting some species of Ammophila arenaria, sand couchgrad (Elytrigia juncea) and lyme grass (Leymus arenarius). Problems can occur when over-harvesting a species, leading to erosion in the area where they are

harvested.

Fig 5. Fishbone diagram.

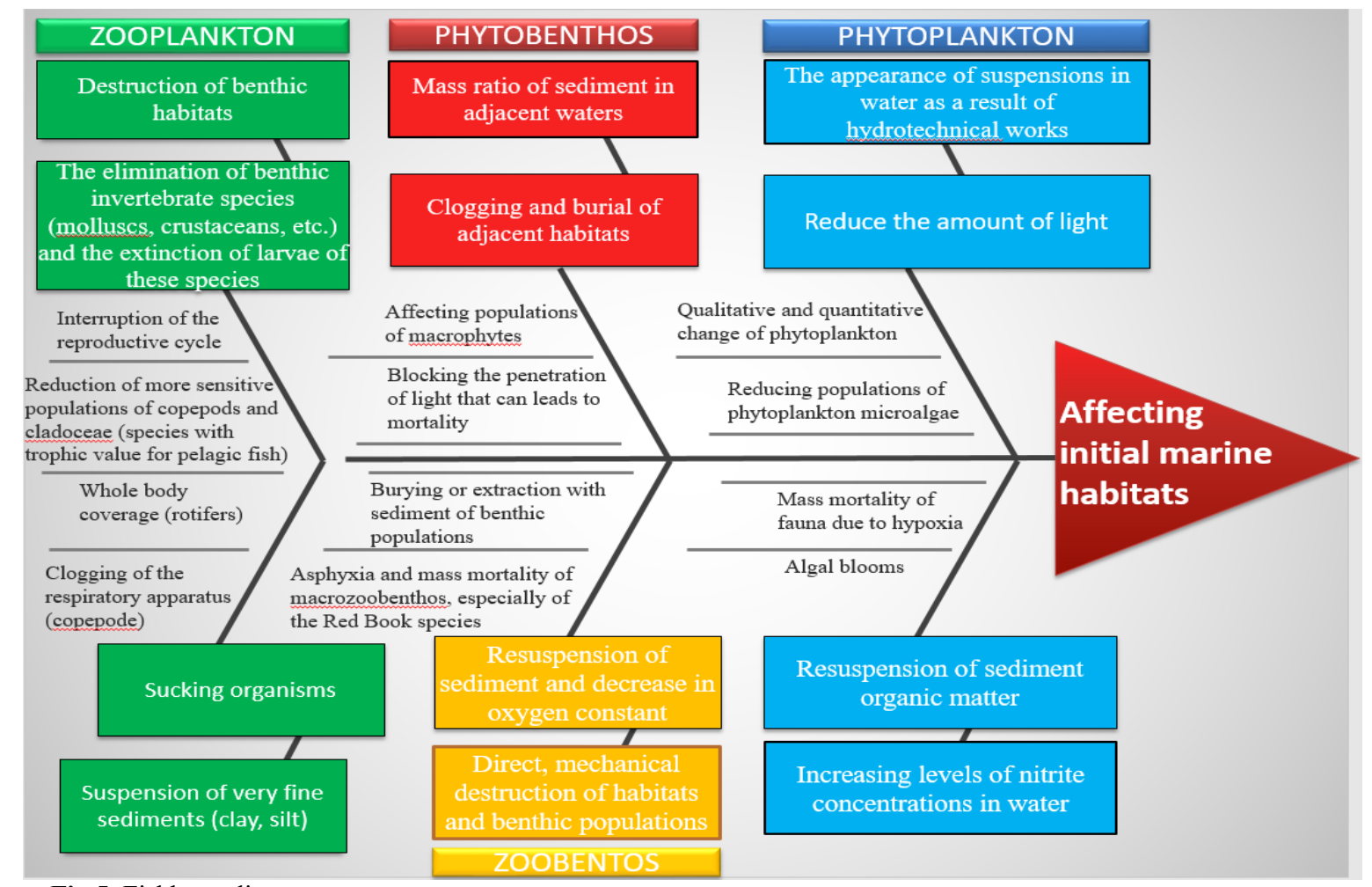

It is very important not to introduce nonindigenous shrubs that can alter the composition of the flora.[3]

\section{Results}

Environmental impact assessment methods include several models such as the Rapid Environmental Impact

Assessment (RIAM) method, the global pollution index method, the Rojanschi classical evaluation method, the simple interaction matrix, the matrix of the Leopold and the Integrated Environmental Impact Assessment and Risk Assessment (SAB) method.

In this paper, the method used was the RIAM method, which includes the establishment of the environmental components subject to the environmental impact assessment study, followed by the qualitative characterization of phytoplacton, phytobenthos, zooplankton and zoobenthos. For each component, we have been awarded notes taking into account the evaluation criteria, Table 1 . Quantification of the risk matrix was performed using the Excel program that has allowed us to quickly analyze different case scenarios..

Above is a fishbone diagram, figure 5, showing the causes and effects of placing "hard work" and especially "soft work" that includes sand extraction and location.

Finally, we estimate the environmental score for using certain defined criteria, which ensures a good quantification of the potential impact for each aspect of the studied environment (figure 6, 7 and 8). 
In the following table, Table 2, on the basis of the fishbone diagram, an analysis of the affected biocenoses according to the severity of the impact described in Table 1 was made in three phases: no intervention (NI), "soft works" intervention (SWI) and "hard work" intervention (HWI).

Table 1. Legend of Table 3.

\begin{tabular}{|c|l|}
\hline $\begin{array}{c}\text { Colour } \\
\text { and score }\end{array}$ & Level of rysk \\
\hline 1 & $\begin{array}{l}\text { Insignificant - with the possibility of minor occurrences in few species or parts of the ecosystem, short and } \\
\text { reversible }\end{array}$ \\
\hline 2 & $\begin{array}{l}\text { Moderate - minor, temporary and reversible damage, habitat damage and migration of aquatic populations, algae } \\
\text { incapable of surviving, impaired water quality but can be quickly resolved }\end{array}$ \\
\hline 3 & $\begin{array}{l}\text { Major - Serious damages with possible remedial measures only through long-term programs, widespread harm, } \\
\text { damage to local species, water quality requires "safe refuge" }\end{array}$ \\
\hline 4 & $\begin{array}{l}\text { Catastrophic - Irreparable damage, death in large numbers, destruction of flora species, contamination of } \\
\text { permanent water and extensive areas, disappearance of species in the Red Book. }\end{array}$ \\
\hline
\end{tabular}

Table 2. Table of impacts produces by choosing one of the three phases.

\begin{tabular}{|l|l|l|l|l|}
\hline $\begin{array}{l}\text { Black Sea } \\
\text { Biocenosis }\end{array}$ & The main causes and effects that affect marine biocenosis & NI & SWI & HWI \\
\hline \multirow{5}{*}{ Zooplankton } & Destruction of benthic habitats & 1 & 2 & 1 \\
\cline { 2 - 5 } & $\begin{array}{l}\text { The elimination of benthic invertebrate species (molluscs, } \\
\text { crustaceans, etc.) and the extinction of larvae of these species }\end{array}$ & 1 & 3 & 2 \\
\cline { 2 - 5 } & Sucking organisms & 1 & 3 & 2 \\
\cline { 2 - 5 } & Suspension of very fine sediments (clay, silt) & 1 & 2 & 2 \\
\hline \multirow{4}{*}{ Poobentos } & Resuspension of sediment and decrease in oxygen constant & 1 & 4 & 3 \\
\cline { 2 - 5 } & Direct, mechanical destruction of habitats and benthic populations & 1 & 4 & 4 \\
\hline & $\begin{array}{l}\text { The appearance of suspensions in water or appearance of toxic } \\
\text { pollutants }\end{array}$ & 1 & 4 & 3 \\
\cline { 2 - 5 } & Reduce the amount of light & 1 & 3 & 4 \\
\cline { 2 - 5 } & Resuspension of sediment organic matter & 1 & 2 & 2 \\
\cline { 2 - 5 } & Increasing levels of nitrite concentrations in water & 1 & 2 & 3 \\
\hline \multirow{2}{*}{ Phytobentos } & Mass ratio of sediment in adjacent waters & 1 & 3 \\
\cline { 2 - 5 } & Clogging and burial of adjacent habitats & 2 \\
\hline
\end{tabular}

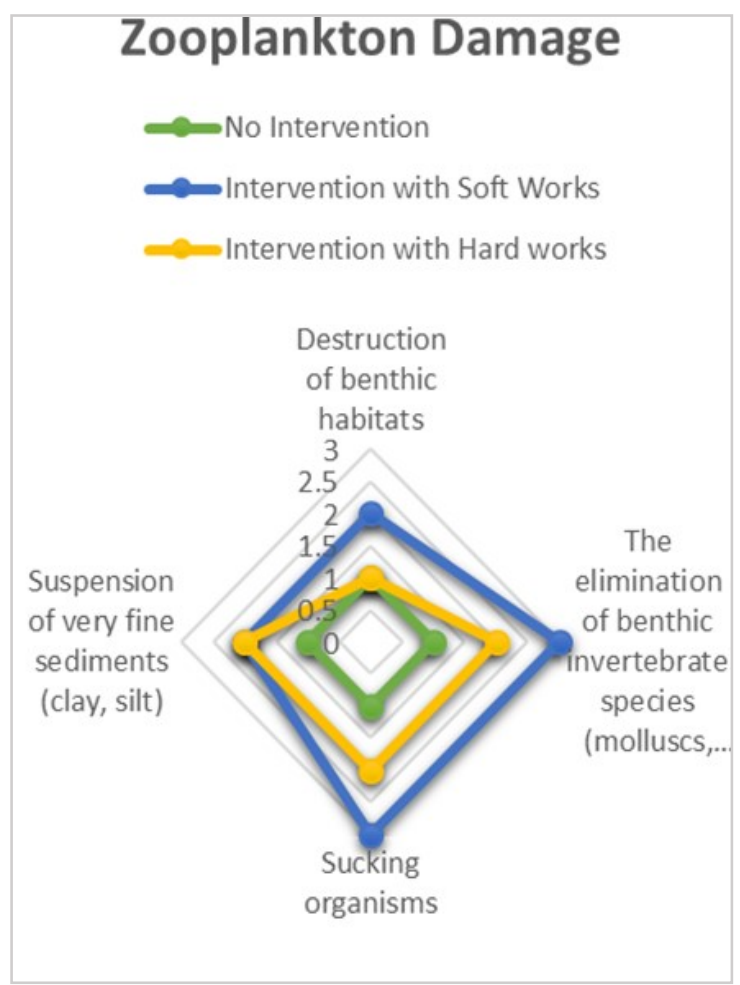

Fig. 6. The damage of zooplankton.

\section{Phytoplankton Damage}
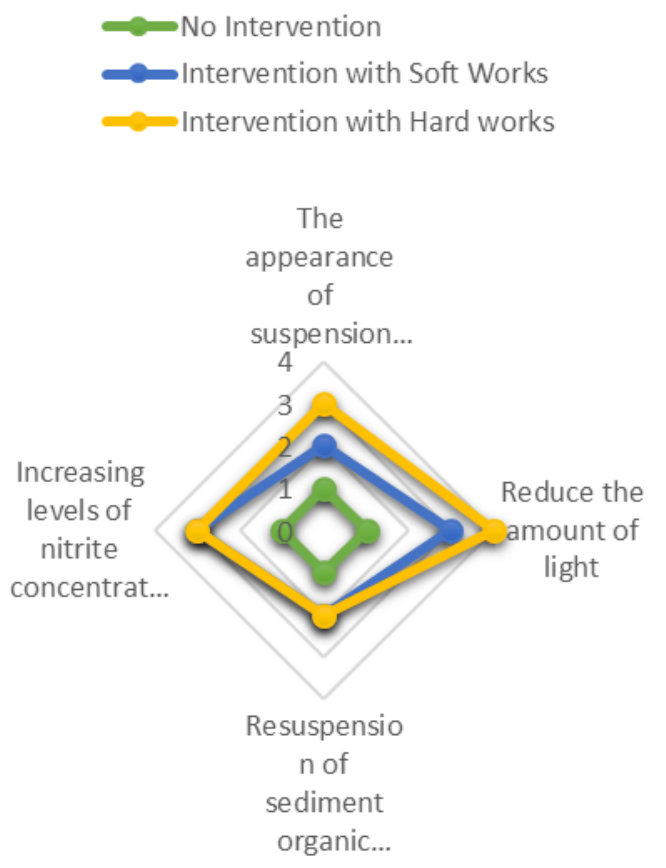

Fig. 7. The damage of phytoplankton. 


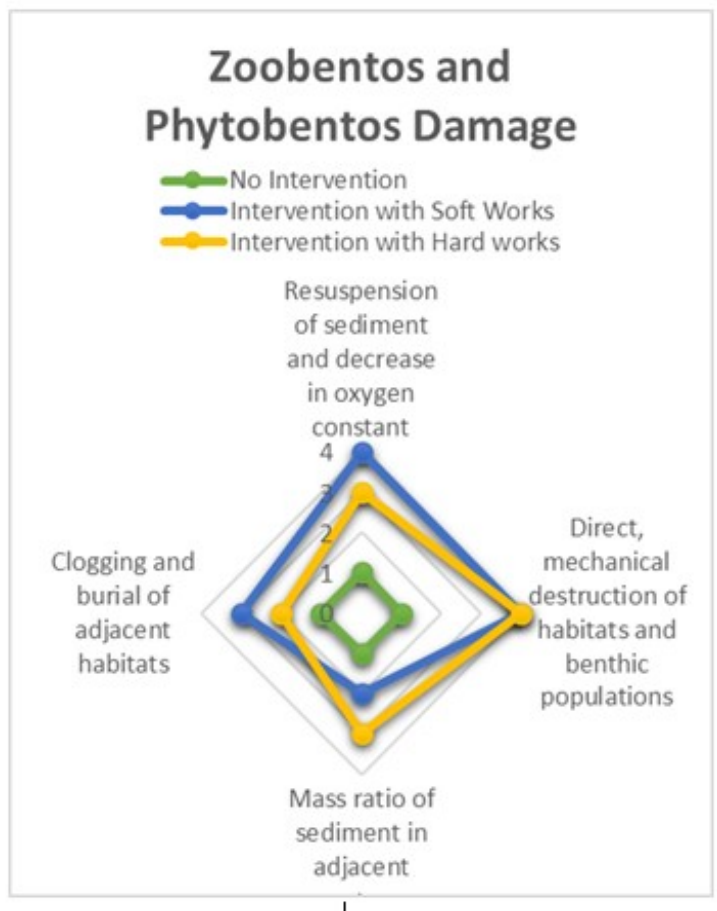

Fig. 8. The damage of zoobentos and phytobentos.

Depending on these discussions it was determined in figures $6,7,8$ the level of damage of the shore protection works compared to the initial case. The equilibrium area is represented by the green colour being the closest to the centre of the polygon.

"Soft works" affect the largest zooplankton by spraying beach areas that involve the extraction of sediments from the sea. Phytoplankton is particularly affected by hydro-technical constructions, but the effects on them are short-lived for some algal species (1-5 years) [3], whereas for other higher species there may be drastic effects.

Biocenosis like zoobenthos and phytobenthos is significantly affected by both types of work and should be carefully addressed at the time of the implementation of a coastal protection project involving these works.

\section{Conclusion}

In conclusion, the impact of coastal protection systems is specific to each case. These may be positive for certain marine ecosystems (emergence of new habitats), but negative for others (feed sediments can have both negative and positive effects on fauna and flora). These ecological impacts are closely related to the quality and quantity of sediment, the location, time and size of the beach project.

For Eforie case, the "hard works" represented by hydrotechnical constructions in the area create new habitats for rocky fauna and flora, as well as habitats for feeding, feeding and resting birds. However, compared to the natural habitats of the rocky shore, diversity is poor, and the biota is dominated by opportunistic species. This environmental impact can be seen as a beneficial effect in some cases. Reducing benthic invertebrates on the hydrographic side of the coastal defense structure due to sediment accumulation can be seen as a negative effect.

However, a long-term environmental impact due to the location of coastal protection systems in Eforie coastal zone is more difficult to quantify, as ecological systems are variable but some general qualitative effects can be discussed.

The benthos structure will allow repopulation of freshly built areas with fauna elements beyond the sand filling area. The dams and artificial reefs will be populated with the same species existing in rocky areas of the substrate.

The inventory of the populations of the benthic edifying species is the basic premise of subsequent actions, which will aim at collecting substrate portions of macrophitobenthos and zoobenthos populations in order to relocate them after the completion of construction works. Also, it is envisaged the possibility of rehabilitation of the affected habitats by planting submerged structures from the natural rock that would allow the restoration of the Cystoseira populations and of the sedimentary areas, respectively, for the resettlement of the Zostera populations.

All acknowledgments for financial support and research project PN-III-P1-1.2-PCCDI-2017-0404 / 31PCCDI/2018, "Holistic impact of renewable energy sources on the environment and climate" (HOLISTICA IMPACTULUI SURSELOR REGENERABILE DE ENERGIE ASUPRA MEDIULUI ŞI CLIMEI) (acronym HORESEC).

\section{References}

1. I.A. Anton, D. Dinu, Wave Simulation with different type of coast potection structure - a comparative approach, International Journal of Environmental Science, 2, 171-176 (2017)

2. I.A. Anton, F.V. Panaitescu, M. Panaitescu, The influence of hydrotechnical constructions on the Romanian morphodynamics coast, Conf. Proc., ISBN 978-619-7408-07-2, 42 , 17, (2017)

3. National Administration Romanian Waters, Basin Administration Dobrogea - Littoral: Environmental Report, Technical Assistance for Project Preparation Priority 5, Implement Appropriate Structure of Natural Risk Prevention in the Most Vulnerable Key Area of Intervention 2 - Reduction of Coastal Erosion evaluation Strategic Environmental Assessments (SEA) Conducted by bloom (2011)

4. National Administration Romanian Waters, Basin Administration Dobrogea - Littoral: Appropiate Assessment Study, The Protection and Rehabilitation of the Southern Black Sea Coast in the Constanta Municipality Area (Mamaia South, Tomis North, Tomis Centre and Tomis South) and Eforie North Area (April 2012)

5. Ospar Commission, Assessment of the impact of coastal defence structures (2009) 